\title{
Market Efficiency in the MENA Equity Markets: Evidence from Newly Developed Tests and Regime Change
}

\author{
Ata Assaf and Husni Charif*
}

\author{
Faculty of Business and Management, University of Balamand, P.O. Box: 100 Tripoli, Lebanon
}

\begin{abstract}
A major issue in financial economics is the behavior of stock market returns over long horizons. This paper provides an empirical investigation of the random walk hypothesis in the MENA equity markets. We use the variance ratio tests developed by Wright (2000), Kim and Wang and Chow Denning (1993) to test for the weak form market efficiency. Then, we use the unit root tests proposed by Saikkonen and Lütkepohl (2002) and Lanne et al. (2002), which allow for a level shift in the data generating process. Our results confirm the stationarity of the MENA equity markets returns in the presence of structural breaks, with the breaks happening mostly during the 2008 and 2009 periods. Further, the findings from our sub-samples indicate that the results from the last sub-periods support the belief that these markets may have been approaching a state of being fairly weak-form efficient, which reflects the future prospects of the MENA countries.
\end{abstract}

Keywords: Random Walk Hypothesis, MENA Equity Markets, Emerging Markets, Weak-form Market Efficiency.

\section{INTRODUCTION}

Testing for efficient market hypothesis has important implications for trading strategies and random walk property of asset returns. Random walks help identify the kinds of shocks that drive stock prices and have an important bearing on the associated potential trading strategies, as is amply suggested by Poterba and Summers (1988) and Lo and Mackinlay (1989). If a given equity price series is, for instance, a random walk, the generating process is dominated by permanent components and hence has no meanreversion tendency. A shock to the series from an initial equilibrium will lead to increasing deviations from its long-run equilibrium. For example, Harvey (1995) concludes that emerging equity markets are less efficient than developed markets, and that higher returns and lower risk can be obtained by incorporating emerging equities in investors' portfolios. Lo and MacKinlay (1988) and Porteba and Summers (1988) explain in details how infrequent or nonsynchronous trading patterns can yield a positively autocorrelated stock price series behavior. For example, Lo and Mackinlay, posit that small-capitalized firms trade less frequently than large-capitalized firms, and therefore, information is impounded first into large-capitalized firms' prices, and then small-capitalized firms', with a lag; and this lag induces a positive serial correlation in the index series that contain these distinct capitalized groups of stocks. Given the market concentration of top large companies that dominate these markets, this explanation is not far-fetched. Another plausible reason

*Address correspondence to this author at the Faculty of Business and Management, University of Balamand, P.O.Box: 100 Tripoli, Lebanon; Tel: (961) 6930250 Ext: 3856; E-mail: husni.charif@balamand.edu.lb

JEL: G14 G01 G15.

E-ISSN: $1929-7092 / 17$ for the positive autocorrelation in these markets' series is the effects of government interventions, exchange rate controls, dividend and/or capital repatriation restrictions, and ownership restrictions (see Errunza, 1983).

Despite the extensive research on the behavior of stock prices in the well-developed financial markets, less is known about it in other markets, specifically in the emerging markets of the Middle East and North African (MENA) region. Research on these markets has focused on the issue of efficiency as well as on their integration with international markets. Butler and Malaikah (1992) examine individual stock returns in both the Kuwaiti and Saudi Arabian markets over the second half of the 1980s and conclude with market inefficiency in both markets. Darrat and Hakim (1997) examine price linkages among three Arab stock markets (Amman, Cairo and Casablanca) and their integration with international markets, and find that these markets are integrated within the region but not at the international level. Darrat and Pennathur (2002) studied economic and financial integration among the countries in the Arab Maghreb region (Algerian, Morocco, and Tunisia) and found that they share a robust relation bringing their financial and economic policies. Abraham et al. (2002) examine the random walk properties of three Gulf stock markets - Kuwait, Saudi Arabia, and Bahrain - after correcting for infrequent trading. They cannot reject the random walk hypothesis for the Saudi and Bahrain markets; however, the Kuwaiti market fails to follow a random walk even after the correction ${ }^{1}$.

\footnotetext{
${ }^{1}$ See El Erian and Kumar (1995), Lim (2008), Al-Loughani (1995) and AlLoughani and Moosa (1997).
}

(C) 2017 Lifescience Global 
Recently, more attention has been given to the MENA region in terms of studying its characteristics, behavior and volatility dynamics. The recent literature details the importance of these markets for risk management, portfolio analysis and market efficiency. For example, Hammoudeh and Li (2008) examined the sudden changes in volatility for five Gulf area Arab stock markets using the iterated cumulative sums of squares (ICSS) and analyzed their impacts on the estimated persistence of volatility. They found that most of the Gulf Arab stock markets are more sensitive to major global events than to local regional factors. For example, the 1997 Asian crisis, the collapse of oil prices in 1998 after the crisis, the adoption of the price band mechanism by OPEC in 2000, and the September 11th attack have been found to have consistently affected the Gulf markets.

Lagoarde-Segot and Lucey (2008) investigated the informational efficiency in a set of seven emerging MENA stock markets. They analyzed the impact of market development, corporate governance and economic liberalization on the latter using a multinomial ordered logistic regression. Their results concluded with heterogeneous levels of efficiency in the MENA stock markets, and their efficiency index seems to be affected mostly by market depth and corporate control, that is, factors directly related to the flow of information. By contrast, variables linked to the overall economic liberalization process do not seem to have explanatory power. Lagoarde-Segot and Lucey (2008) showed that Turkey and Israel showed the strongest evidence of weak-form efficiency. These markets were followed by Jordan, Tunisia and Egypt, with Lebanon and Morocco lagging behind. They associated that with the fact that Turkey and Israel are endowed with more liquid and capitalized stock markets and have well-developed financial systems. Strong capitalization in Jordan is counterbalanced by the fact that banks represent $50 \%$ of market capitalization and by the absence of a secondary market. Tunisia, Egypt, Lebanon and Morocco constitute smaller markets, although one limitation of these results is that they do not fully incorporate the recent developments in the Cairo Stock Exchange.

Brooks (2007) studied a set of emerging markets including those from the MENA region using the APARCH model and explored the applicability of the model to those markets. His findings were as follows. First, unlike developed markets where a power term of unity and a conditional standard deviation model appears to be appropriate, emerging markets demonstrate a considerably greater degree of power values. Second unlike developed markets where nonnormal conditional error distributions appear to fit the data well, there are a set of emerging markets for which estimation problems arise with a conditional $t$ distribution, and a conditional normal distribution appears to be the preferred option. Third, the degree of volatility asymmetry appears to vary across the set of emerging markets, with the Middle Eastern and African markets having very different volatility asymmetry characteristics to those of the Latin American markets.

Nikkinen et al. (2008) used data from 53 equity markets including the MENA markets to investigate the short term impact of the September 11 attacks on markets' returns and volatility. They found that the impact of the attacks resulted in significant increases in volatility across regions and over the study period. However, stock returns experienced significant negative returns in the short-run but recovered quickly afterwards. Nevertheless, they find that the impact of the attacks on financial markets varied across regions and implied that the less integrated regions (i.e., MENA) are with the international economy, the less exposed they are to shocks. They indicated that the MENA region provides investors with the highest returns and the lowest volatility, in which it shows statistically significant higher stock returns and lower volatility compared with each of the other regions. In the post-September period, the MENA region maintained the lowest volatility compared with other regions, either shortly after the attacks or even over a longer period. In terms of stock returns, MENA shows statistically significant positive stock returns after the attacks compared with each region without exception. In longer periods, the MENA region seems to underperform other regions significantly for 3 months following the attacks. And over a 6- month period following the attacks the MENA region was found to still underperform other regions.

Lagoarde-Segot and Lucey (2007) looked at the potential diversification benefits in the MENA region using local currencies and dollar transactions. They concluded that these markets should attract more portfolio flows in the future. Analyzing the patterns of portfolio weights across optimization methodologies allowed the authors to make certain deduction concerning the country level risk-to-return tradeoff. For instance, market attractivity in Morocco and Tunisia seems to be primarily driven by low risks rather than high returns. Morocco obtains the highest weights when returns are not taken into account, and when risk 
is assimilated to downside deviation. The opposite situation is found in Jordan and Israel. Portfolio allocations in these two countries are very small when the optimization techniques rely on downside risk minimization, and overall, these two markets seem to display both high returns and risks, in line with the standard view for emerging markets. Interestingly, portfolio allocations in Egypt seem to be very sensitive to the selected measure of risk. This suggests the predominance of upwards volatility in the Egyptian market, a not surprising feature considering the last decade's massive capitalization increases in the Egyptian market. Portfolio allocations are the most unstable in Turkey, and this dynamic might reflect the multiplier impact of the 2001 crisis on downside volatility in the Turkish market.

In general, the MENA region is considered a part of the emerging markets and these markets are typically much smaller, less liquid, and more volatile than wellknown world financial markets (Domowitz, Glen, and Madhavan (1998)). There is also more evidence that these markets may be less informationally efficient, due to poor-quality information, high trading costs, and less competition, and their industrial organization is often quite different from that in developed economies. Further, the industrial organization found in these economies is often quite different from that in developed economies. All of these conditions and others may contribute to a different behavior than observed in industrialized stock markets ${ }^{2}$.

Given the divergent conclusions of this research, further insights should be obtainable through an investigation of alternative stock market returns, in particular, returns from MENA emerging stock markets. The focus on these markets is appropriate for a number of reasons. First, these countries are part of the countries in the Middle East and North African region and are becoming an increasingly important component of the regional economy, with their equity market becoming an integral segment of the regional stock markets. Understanding the behavior of these markets is thus an important undertaking. Second, these markets allow comparison of developed markets with maturing markets to determine if the returnsgenerating processes and presence or absence of long-range dependence depends on the degree of

\footnotetext{
${ }^{2}$ Studies on the emerging markets in the Mediterranean include Harvey (1995), Bekaert and Harvey (1995,1997), Errunza (1994) and Choudhry (1996). For an overview of the state of equity markets in some Middle Eastern countries, see El Erian and Kumar (1995).
}

market development. Third, the presence of longmemory dynamics in equity prices would provide evidence against the weak form of market efficiency as it implies non-linear dependence in the moments of the distribution and hence a potentially predictable component in the series dynamics. Fourth, the presence of fractal structure in financial prices may reflect fractal dynamics in the underlying economy, which, in turn, would be of value in modeling business cycles. Fifth, as the volatility dynamic plays a very important role in derivative pricing, it may be beneficial to incorporate the long-term volatility structure in deriving pricing formulas. Indeed, Bollerslev and Mikkelsen (1996) presented results showing that it may be important to model the long memory volatility correctly when pricing contracts with long maturity, such as index options and futures.

We conclude that this set of markets, even with their different institutions and information flows than the developed market, present similar market structure to the preponderance of studies employing other developed markets data. The implication of our results is that differences in institutions and information flows in MENA emerging equity markets are not that important enough to affect the valuation process of equity securities and produce similar results to those occurring in developed markets.

The paper is organized as follows. Section 2 provides a financial and economic background of MENA equity markets. Section 3 provides an overview of the theoretical background and describes the tests and estimators employed. Section 4 presents the data and empirical results, including the regime shifts. Section 5 contains a summary of our findings and concluding remarks.

\section{MENA EQUITY MARKETS: FINANCIAL AND ECONOMIC CHARACTERISTICS}

Over the last decade, the empirical finance literature has been concerned with the financial dynamics of the world major stock markets. Recently, there has been a shift in attention to "emerging markets" (Bekaert and Harvey (1997), DeSantis and Imrohoroglu (1997). An emerging market is a market that: 1) has securities that trade in a public market; 2 ) is not a developed market (as defined by countries covered within the Morgan Stanley Capital International Indices or Financial Times Indices); 3 ) is of interest to global institutional investors; and 4) has a reliable source of data. The new focus stems from the fact that these markets present portfolio 
and fund managers a venue to enhance and optimize their portfolios. For example, Bekaert and Harvey (1997) found that stock market returns in emerging markets were high and predictable but lacked strong correlation with major markets. As emerging markets mature, they are likely to become increasingly more important in offering investment opportunities. The MENA (Middle East and North Africa) region is part of these markets and offers those opportunities to investors. The importance of this region is that all MENA equity markets are open to foreign investor participation and also allow repatriation of dividends and capital. Apart from Jordan where foreign investors are restricted to certain sectors but allowed to own $99 \%$ of the tourism share capital, the three others markets (Egypt, Morocco, and Turkey) have no restrictions on foreign investors ${ }^{3}$. Despite their openness, these markets remain somewhat unsophisticated and MENA's combined market capitalization remains small -- both in comparison to other regions, and in proportion to its overall GDP.

The underdevelopment of the region's stock markets is the result of several factors, not least of which is the fact that MENA still attracts a small proportion of the world's foreign direct investment (FDI). According to figures obtained from the Institute of International Finance, the Middle East and African attracted just US\$10bn of foreign direct investment in 2001 , compared with US $\$ 50.4 \mathrm{bn}$ for Latin American and almost US\$70bn for Asia. The Middle East and African share represents just $6.7 \%$ of total equity investment inflows to emerging markets. A further drain on investor's confidence is the memory of recent stock market crashes that took place at the end of the last decade. For example, investors in Egypt were burned by their own stock market crash of 1997-1998, precipitated by the East Asian financial crisis and the subsequent emerging markets financial crisis. Nevertheless, as these countries launch their privatization programs with the government sell-offs, foreign investors will be more encouraged putting their money into MENA countries. The resultant link between privatization and stock market vitality is clear. Egypt is a case in point, where the development of the market has closely tracked the progress of the country's privatization program (faltering when share

${ }^{3}$ For issues related to market efficiency and organizational structure, look at Claessens et al. (1995) and Karemera et al. (1999) for Jordan and Turkey; Ghysels and Cherkaoui (2003) for Morocco, and Appiah-Kusi and Menyah (2003) for Egypt and Morocco. issues were under-subscribed, and rising strongly when the privatization program picked up pace in 1996).

The comparative underdevelopment of MENA stock markets has focused the minds of many MENA governments in addressing them and several stock markets are working to upgrade their trading infrastructure and systems. For example, Egypt revitalized its capital market by adopting a computerbased screen trading system, a circuit breaker and has one 4-hours trading session. Between 1996 and 2000, the market went through volatile and sluggish periods, due to speed up of the privatization program. In early 2000, the market peaked recording new highs, but the outstanding performance did not continue and the market sloped downwards to record new lows due to deterioration in monetary indicators and tension in the foreign exchange market. In Jordan, the Securities Law, No. 23 introduced in 1997, involved institutional changes in the capital market, the use of electronic trading system, and elimination of obstacles to investment. During 1999, the Amman Stock Exchange (ASE) was established and considered one of the largest in the region with the government selling stakes in different Industries. However, the positive signs, such as reorganization of more than $\$ 800$ million in Paris Club debt, and IMF approval of a $\$ 220$ million loan packaged, failed to boost market activity. By 2000 , the ASE began implementing new directives to secure settlement of trades and provide assurance to dealers of timely settlements and by 2001, S\&P revised its outlook on Jordan's long-term foreign currency rating to positive from stable and the Amman Stock Exchange 's performance was the strongest in the Middle East.

The reforms in Morocco started earlier and in 1995, a professional association of the market makers was created and a document called Protocole de Place organizes the procedures, payment delivery and compensation for the CSE. As a result, the CSE was included in the IFC Emerging Market database in 1996 together with stock exchanges from two other countries, Egypt and Russia ${ }^{4}$. By 2000, Morocco concluded a free trade zone agreement with the European Union, and in 2001, Morocco was announced to be included in the $\mathrm{MSCl}$ Emerging Markets Index Series. Then the government

${ }^{4}$ The IFC attributed a weight of $0.4 \%$ to the Morrocan index in the computation of the global emerging market index. This weight exceeds that of Egypt $(0.1 \%)$ and some of the previously incorporated emerging markets such as Jordan $(0.2 \%)$. 
implemented some measures, like individual investors were exempted from the $10 \%$ profit tax, to boost stock market activity, but without much success during this period. In Turkey, between 1997 and 1998, the government targeted $\$ 5$ billion in privatization programs in order to balance the budget and implemented a "shock program" to rein in inflation and eased tax legislation by lowering the stock holding period from one year to three months to be exempt from capital gain taxes. In 1999, a banking law was passed and the government measures won the support of the IMF for fighting inflation and financial reforms. However, by 2000 , a banking crisis was triggered by anxiety over bank liquidity problems, but then the crisis was contained with an IMF package and new capital markets and banking laws were initiated. In 2001, weak banks were sold and the central bank let the lira to float. Share prices plunged and the Central Bank warned about the liquidity needs after the September attack. By the end of 2001, Turkey agreed to strengthen its banking system and accelerate privatization, which later had its impact on the stock market performance.

Overall, these markets showed a noticeable growth in market capitalization, the value of traded shares, turnover ratio and the number of listed companies. This growth is associated with the massive privatization plans introduced in the region; the sale of government assets to private firms; and the considerable efforts devoted towards enhancing the efficiency, depth, and liquidity of MENA stock markets. Generally, these markets have gone through different changes in the last few years, and as these countries liberalize their financial markets, the dynamics of asset returns in their equity markets are likely to be affected.

\section{EMPIRICAL METHODOLOGY}

Since the seminal work of Lo and Mackinlay (1988, 1989) and Poterba and Summers (1988), the standard variance ratio test and its improved modifications have been widely used to test for the unpredictability of price changes, including the multiple variance ratio test of Chow and Denning (1993), sign and rank tests of Wright (2000), wild bootstrap of Kim (2006), and power-transformed test of Chen and Deo (2006).

The VR test is based on the property that, if return is purely random walk, the variance of $k$-period return (or $k$-period differences), $y_{t}-y_{t-k}$, of the time series $y_{t}$, is $k$ times the variance of the one-period return (or the difference), $y_{t}-y_{t-k}$. Hence, the VR at lag $k$, $\operatorname{VR}(k)$, defined as the ratio of $1 / k$ times the variance of $k$-period return to that of one-period return, should be equal to one for all values of $k$.

Before conducting the variance ratio tests, we subject the series to a unit root test that takes into account structural breaks.

\subsection{Saikkonen and Lütkepohl (2002) and Lanne et al. (2002) Unit Root Tests}

We use the unit root tests proposed by Saikkonen and Lütkepohl (2002) and Lanne et al. (2002). The model proposed is represented by:

$y=\mu_{0}+\mu_{1} t+f_{t}(\theta)^{\prime} \gamma+\varepsilon_{t}$

$f_{t}(\theta)^{\prime} \gamma$, is a shift function, which is added to the deterministic term $\mu_{t}$ of the data generating process. $\theta$ and $\gamma$ are unknown parameters or parameter vectors and the errors $\varepsilon_{t}$ are generated by an $A R(p)$ process with possible unit root. Saikkonen and Lütkepohl (2002) and Lanne et al. (2002), proposed three possible shift functions: a shift dummy, an exponential distribution function, and a rational function in the lag operator. We only consider the shift dummy variable function with shift date $T_{B}$.

$f_{t}^{(1)}=d_{1 t}:=\left\{\begin{array}{l}0, t<T_{B} \\ 1, t \geq T_{B}\end{array}\right\}$

This function does not involve any extra parameter $\theta$. In the shift term $f_{t}^{(1)} \gamma$, the parameter $\gamma$ is a scalar and differencing this shift function leads to an impulse dummy.

Saikkonen and Lütkepohl (2002) and Lanne et al. (2002) proposed unit root tests for the model (1) which are based on estimating the deterministic term first by a generalized least squares (GLS) procedure under the unit root null hypothesis and substracting it from the original series. Then an ADF type test is performed on the adjusted series with the critical values tabulated in Lanne et al. (2002), since as in the case of the ADF statistic, the asymptotic null distribution is nonstandard. In conducting the tests, one has to decide on the AR order and the shift date $T_{B}$. Since the tests are conducted with the break date is unknown, Lanne et al. (2001) recommended to choose a reasonably large AR order in a first step and then pick the break date which minimizes the GLS objective function used to estimate 
the parameters of the deterministic part. Simulations and critical values are tabulated in Lanne et al. (2002) .

\subsection{Lo-MacKinlay Test}

To explain this procedure, suppose that $x_{t}$ is an asset return at time $t$, where $t=1, \ldots, T$. Following Wright (2000), we write

$$
\begin{aligned}
V R(x, k= & \left\{1 / T k \sum_{t=k}^{T}\left(x_{t}+x_{t-1}+\ldots+x_{t-k+1}-k \hat{\mu}\right)^{2}\right\} / \\
& \left\{1 / T \sum_{t=1}^{T}\left(x_{t}-\hat{\mu}\right)^{2}\right\}
\end{aligned}
$$

Where $\hat{\mu}=\sum_{t=1}^{T} x_{t}$. This is an estimator for the unknown population $V R$, donated as $V(k)$, which is the ratio of $1 / k$ times the variance of the $k$-period return to the variance of the one-period return. Lo and MacKinlay (1988) showed that if $x_{t}$ is independent and identically distributed (iid), then under null hypothesis that $V(k)=1$,

$\left.M_{1}(x, k)=(V R(x ; k)-1)\right)\left(\frac{2(2 k-1)(k-1)}{3 k T}\right)^{1 / 2}$

follows the standard normal distribution asymptotically. To accommodate $x_{t}$ 's exhibiting conditional heteroscedasticity, Lo and MacKinlay (1988) proposed a heteroscedaticity robust test statistic

$M_{2}(x, k)=(V R(x ; k)-1)\left(\sum_{j=1}^{k=1}\left[\frac{2(k-j)}{k}\right]^{2} \delta_{j}\right)^{-1 / 2}$

which follows the standard normal distribution asymptotically under null hypothesis that $V(k)=1$, where

$\delta_{j}=\left\{\sum_{t=j+1}^{T}\left(x_{t}-\hat{\mu}\right)^{2}\left(x_{t-j}-\hat{\mu}\right)^{2}\right\} /\left\{\left[\sum_{t=1}^{T}\left(x_{t}-\hat{\mu}\right)^{2}\right]^{2}\right\}$

The $M_{2}$ test is applicable to $x_{t}$ 's generated from a martingale difference time series (see Assumption $\mathrm{H}^{*}$ of Lo and MacKinlay, 1988). The usual decision rule for the standard normal distribution applies to both tests.

\footnotetext{
${ }^{5}$ See Saikkonen and Lütkepohl (2002) and Lanne et al. (2002) for further explanation on the procedure, where the unit root test is based on an auxiliary regression model.
}

\subsection{Chow-Denning Test}

The Lo-MacKinlay test is an individual test where the null hypothesis is tested for an individual value or $k$. The question is to whether or not a stock return is mean-reverting requires that the null hypothesis hold true for all values of $k$. Chow-Denning (1993) devise a joint test with controlled size as follows: under the null hypothesis, $V\left(k_{i}\right)=1$ for $i=1, \ldots$, I against alternative hypothesis that $V\left(k_{i}\right) \neq 1$ for some $i$. Chow and Denning's (1993) test static is

$M V_{1}=\sqrt{T} \max _{1 \leq i \leq l}\left|M_{1}\left(x ; k_{i}\right)\right|$

where $M_{1}\left(x ; k_{i}\right)$ is defined in (2). This is based on the idea that the decision regarding the null hypothesis can be made based on the maximum absolute value of the individual VR statistics. ${ }^{7}$ The null hypothesis is rejected at a level of significance if the $\mathrm{MV}_{1}$ statistic is greater than the $\left[1-\left(\alpha^{*} / 2\right)\right]$ th percentile of the standard normal distribution where $\alpha^{*}=1-(1-\alpha)^{1 / l}$.

Similarly, the heteroskedasticity-robust version of the Chow-Denning test $\mathrm{MV}_{2}$ can be written as

$$
M V_{2}=\sqrt{T} \max _{1 \leq i \leq l}\left|M_{2}\left(x, k_{i}\right)\right|
$$

which is the joint test using $\mathrm{M}_{2}(x, k)$ given in (3), and it has the same critical values as $M V_{1}$.

\subsection{Wright's Rank and Sign VR Tests}

As already noted, both Lo-MacKinlay and ChowDenning tests are asymptotic tests, whose sampling distributions are approximated based on their limiting distributions, Lo and MacKinlay (1989) find that the sampling distribution of the VR statistic can be far from normal in finite sample. As Deo and Richardson (2003) point out, the Lo-MacKinlay test is inconsistent with respect to the variety of mean reverting alternatives where the limiting power function is bounded by a number less than one. In this respect, Wright's (2000) tests have two advantages over Lo-MacKinlay and Cow-Denning tests when sample size is relatively small: (i) as the sign and rank tests have exact sampling distribution, there is no need to resort to asymptotic approximation and (ii) the tests may be more powerful than the conventional VR tests when the data are highly non-normal (Wright, 2000).

Wright (2000) derives rank and sign statistics as follows. Let $r\left(x_{t}\right)$ be the rank of $x_{t}$ among $x_{t}$ 's. Consider the standardized rank $r_{1 t}=\left[\left(r\left(x_{t}\right)-0.5(T+1)\right.\right.$ 
/ $[(T-1)(T+1) / 12]$. Under the null hypothesis that $\mathrm{x}_{\mathrm{t}}$ is generated from an i.i.d. sequence, $r\left(x_{t}\right)$ is a random of the numbers of $1, \ldots, T$ with equal probability. Wright (2000) suggests the static

$$
\left.\begin{array}{rl}
R_{1}= & \left(\frac{(T k)^{-1} \sum_{t=k}^{T}\left(r_{1 t}+r_{1 t-1}+\ldots .+r_{1 t-k+1}\right)^{2}}{T^{-1} \sum_{t=1}^{T} r_{1 t}^{2}}-1\right.
\end{array}\right)
$$

which follows an exact sampling distribution (see Proposition 1 of Wright, 2000). Wright proposes the use of alternative standardization $r_{2 t}=\phi^{-1}\left[r\left(x_{t}\right) /(T+1)\right]$, where $\phi$ is the standard normal cumulative distribution function. This leads to the $\mathrm{R}_{2}$ static, which can be written as follows:

$$
\begin{aligned}
& R_{2}=\left(\frac{(T k)^{-1} \sum_{t=k}^{T}\left(r_{2 t}+r_{2 t-1}+\ldots . .+r_{2 t-k+1}\right)^{2}}{T^{-1} \sum_{t=1}^{T} r_{2 t}^{2}}-1\right) \\
& \left(\frac{2(2 k-1)(k-1)}{3 k T}\right)^{-1 / 2}
\end{aligned}
$$

\begin{tabular}{|c|c|c|c|c|c|c|}
\hline & Bahrain & Egypt & Jordan & Kuwait & Lebanon & Morocco \\
\hline Mean & -0.0992 & 0.0107 & -0.046 & -0.0124 & 0.020 & 0.034 \\
\hline S.D. & 1.35 & 1.849 & 1.331 & 1.528 & 1.586 & 1.227 \\
\hline Skewness & -3.413 & -1.054 & -0.694 & -1.045 & -0.018 & -0.339 \\
\hline Kurtosis & 62.77 & 11.217 & 11.134 & 13.01 & 17.614 & 6.309 \\
\hline $\mathrm{JB}$ & $\begin{array}{l}272065 \\
(0.000)\end{array}$ & $\begin{array}{l}5409.4 \\
(0.000)\end{array}$ & $\begin{array}{l}5118.9 \\
(0.000)\end{array}$ & $\begin{array}{c}7866.02 \\
(0.000)\end{array}$ & $\begin{array}{c}16054.09 \\
(0.000)\end{array}$ & $\begin{array}{l}857.75 \\
(0.000)\end{array}$ \\
\hline $\begin{array}{l}\rho(1) \\
\rho(2) \\
\rho(3)\end{array}$ & $\begin{array}{c}0.073 \\
0.039 \\
-0.013\end{array}$ & $\begin{array}{l}0.127 \\
0.014 \\
0.072\end{array}$ & $\begin{array}{l}0.058 \\
0.009 \\
0.018\end{array}$ & $\begin{array}{l}0.048 \\
0.043 \\
0.037\end{array}$ & $\begin{array}{c}0.133 \\
-0.049 \\
0.020\end{array}$ & $\begin{array}{c}0.200 \\
0.003 \\
-0.022\end{array}$ \\
\hline$Q(12)$ & $\begin{array}{c}32.00 \\
(0.000)\end{array}$ & $\begin{array}{c}50.03 \\
(0.000)\end{array}$ & $\begin{array}{c}20.21 \\
(0.063)\end{array}$ & $\begin{array}{c}36.25 \\
(0.000)\end{array}$ & $\begin{array}{c}52.42 \\
(0.000)\end{array}$ & $\begin{array}{c}87.53 \\
(0.000)\end{array}$ \\
\hline $\begin{array}{l}\rho_{r s}(1) \\
\rho_{r s}(2) \\
\rho_{r s}(3)\end{array}$ & $\begin{array}{l}0.048 \\
0.030 \\
0.012\end{array}$ & $\begin{array}{l}0.175 \\
0.055 \\
0.049\end{array}$ & $\begin{array}{l}0.118 \\
0.181 \\
0.164\end{array}$ & $\begin{array}{l}0.137 \\
0.114 \\
0.140\end{array}$ & $\begin{array}{l}0.226 \\
0.106 \\
0.074\end{array}$ & $\begin{array}{l}0.245 \\
0.136 \\
0.086\end{array}$ \\
\hline$Q_{s}(20)$ & $\begin{array}{c}17.32 \\
(0.138)\end{array}$ & $\begin{array}{l}132.50 \\
(0.000)\end{array}$ & $\begin{array}{l}445.41 \\
(0.000)\end{array}$ & $\begin{array}{l}567.92 \\
(0.000)\end{array}$ & $\begin{array}{l}157.23 \\
(0.000)\end{array}$ & $\begin{array}{l}323.16 \\
(0.000)\end{array}$ \\
\hline & Tunisia & Oman & UAE & Qatar & ArabMarket & GCC \\
\hline Mean & 0.0285 & -0.0189 & -0.064 & 0.001 & -0.018 & -0.027 \\
\hline S.D. & 1.058 & 1.414 & 2.121 & 1.704 & 1.109 & 1.303 \\
\hline Skewness & 0.122 & -1.424 & -0.662 & -0.66 & -1.414 & -1.422 \\
\hline Kurtosis & 9.569 & 27.99 & 14.01 & 13.35 & 14.50 & 15.38 \\
\hline $\mathrm{JB}$ & $\begin{array}{c}3248.35 \\
(0.000)\end{array}$ & $\begin{array}{c}47566.37 \\
(0.000)\end{array}$ & $\begin{array}{r}9242.87 \\
(0.000)\end{array}$ & $\begin{array}{l}8192.1 \\
(0.000)\end{array}$ & $\begin{array}{c}10546.4 \\
(0.000)\end{array}$ & $\begin{array}{c}12127.16 \\
(0.000)\end{array}$ \\
\hline $\begin{array}{l}\rho(1) \\
\rho(2) \\
\rho(3)\end{array}$ & $\begin{array}{c}0.110 \\
0.046 \\
-0.038\end{array}$ & $\begin{array}{c}0.090 \\
0.035 \\
-0.014\end{array}$ & $\begin{array}{l}0.117 \\
0.064 \\
0.032\end{array}$ & $\begin{array}{l}0.065 \\
0.035 \\
0.048\end{array}$ & $\begin{array}{l}0.127 \\
0.096 \\
0.082\end{array}$ & $\begin{array}{l}0.107 \\
0.096 \\
0.063\end{array}$ \\
\hline$Q(12)$ & $\begin{array}{c}40.82 \\
(0.000)\end{array}$ & $\begin{array}{c}38.55 \\
(0.000)\end{array}$ & $\begin{array}{c}44.98 \\
(0.000)\end{array}$ & $\begin{array}{c}21.82 \\
(0.040)\end{array}$ & $\begin{array}{c}81.04 \\
(0.000)\end{array}$ & $\begin{array}{c}67.28 \\
(0.000)\end{array}$ \\
\hline $\begin{array}{l}\rho_{r s}(1) \\
\rho_{r s}(2) \\
\rho_{r s}(3)\end{array}$ & $\begin{array}{c}0.166 \\
0.0164 \\
0.122\end{array}$ & $\begin{array}{l}0.148 \\
0.142 \\
0.133\end{array}$ & $\begin{array}{l}0.116 \\
0.144 \\
0.086\end{array}$ & $\begin{array}{l}0.129 \\
0.200 \\
0.087\end{array}$ & $\begin{array}{l}0.127 \\
0.096 \\
0.082\end{array}$ & $\begin{array}{l}0.139 \\
0.141 \\
0.140\end{array}$ \\
\hline$Q_{s}(20)$ & $\begin{array}{l}156.63 \\
(0.000)\end{array}$ & $\begin{array}{l}269.96 \\
(0.000)\end{array}$ & $\begin{array}{l}378.37 \\
(0.000)\end{array}$ & $\begin{array}{l}409.93 \\
(0.000)\end{array}$ & $\begin{array}{c}81.04 \\
(0.000)\end{array}$ & $\begin{array}{l}342.95 \\
(0.000)\end{array}$ \\
\hline
\end{tabular}

Table 1: Summary Statistics for Daily Returns

Notes: J.B. is the Jarque-Bera normality test statistic with 2 degrees of freedom with the corresponding $p$-values; $\rho$ (k) is the sample autocorrelation coefficient at lag $k$ and $Q(k)$ is the Box-Ljung portmanteau statistic based on $k$-squared autocorrelations. $\rho_{r s}(k)$ are the sample autocorrelation coefficients at lag $k$ for squared returns and $Q_{s}(20)$ is the Box-Ljung portmanteau statistic based on 20 -squared autocorrelations. 
The $R_{2}$ test in (9) shares the same sampling distribution as $R_{1}$. The critical values of these tests can be obtained by stimulating their exact distributions, as shown in Table 1 of Wright (2000).

Similarly, Wright (2000) derives a sign-based test static. Consider $s_{t}=2 u\left(x_{t}, 0\right)=1\left(x_{t}>0\right)-0.5$ while 1 (.) is the indicator function which takes the value 1 if the condition inside the bracket is satisfied and 0 otherwise. Under the null hypothesis that $x_{t}$ is a martingale difference sequence (Assumptions $A 1$ and A2 of Wright, 2000) whose unconditional mean is zero, $s_{t}$ is an i.i.d. sequence with mean 0 and variance equal to 1 , which takes the value 1 and -1 with equal probability of 0.5 . Based on this, Wright (2000) proposed the sign-based test statistic

$$
\begin{aligned}
& S_{1}=\left(\frac{(T k)^{-1} \sum_{t=k}^{T}\left(s_{t}+s_{t-1}+\ldots .+s_{t-k+1}\right)^{2}}{T^{-1} \sum_{t=1}^{T} r_{t}^{2}}-1\right) \\
& \left(\frac{2(2 k-1)(k-1)}{3 k T}\right)^{-1 / 2}
\end{aligned}
$$

Similarly to $R_{1}$ and $R_{2}$ tests, the critical values of the $S_{1}$ test can be obtained by stimulating its exact sampling distribution (see Proposition 2 of Wright, 2000). It should be mentioned that Wright's (2000) $S_{2}$ is not considered here, as his Monte Carlo simulation results clearly indicate that its size and power properties are quite inferior to those of $S_{1}$. The critical values of the $R_{1}, R_{2}$ and $S_{1}$ tests associated with the sample sizes and holding periods are given in Table 3.

\subsection{Whang-Kim Subsampling Test}

The Whang-Kim test uses the subsampling technique of Politis, Romano, and Wolf (1997), which is a data-intensive method of approximating the sampling distribution. The Monte Carlo experiment results reported in Whang and Kim (2003) confirm that their new VR test shows excellent power in small samples, coupled with little or no serious size distortions.

To test the null hypothesis that $V\left(k_{i}\right)=1(i=1, \ldots, l)$, Whang and Kim (2003) consider the statistic

$M V_{3}=\sqrt{T} g_{N}\left(x_{1}, \ldots ., x_{T}\right)$

where $g_{t}\left(x_{t}, \ldots . ., x_{T}\right)=\max _{1 \leq i \leq l}\left|V R\left(x, k_{j}\right)-1\right|$ and VR $(x ; k)$ is as defined in (1). The sampling distribution function for the $\mathrm{MV}_{3}$ statistic is written as
$G_{T}(x)=P\left(\sqrt{T} g_{T}\left(x_{x}, \ldots, x_{T}\right) \leq x\right)$

Since the distribution function given in (10) is unknown and analytically intractable, Whang and Kim (2003) use the following approximation. Consider a subsample $\left(x_{t}, \ldots, x_{t-b+1}\right)$ of size $b$ for $t=1, \ldots, T-b+1$. The statistic $\mathrm{MV}_{3}$ calculated from the sample donated as $g_{T, b, 1}=g_{b}\left(x_{t}, \ldots, x_{t-b+1}\right)$. Then $G_{T}(x)$ is approximated in the distribution function obtained by the collection of $\mathbf{g}_{T, b, t}$ 's calculated from all individual samples. It can be written as $\hat{G}_{T, b}(x)=(T-b+2)^{-1} \sum_{t=0}^{T-b+1} 1\left(\sqrt{b} g_{T, b, t} \leq x\right)$ where 1 (.) is the indicator function that takes 1 if the condition inside the bracket is satisfied and 0 otherwise.

The $100(1-\alpha) \%$ critical value for the test can be calculated as the $(1-\alpha)^{\text {th }}$ percentile of the $\hat{G}_{T, b}$ while the $p$-value of the test estimated as $1-\hat{G}_{T, b}\left(M V_{3}\right)$. The null hypothesis that $V\left(k_{i}\right)=1(i=1, \ldots, l)$ is rejected at the level of significance $\alpha$ if the observed $\mathrm{MV}_{3}$ is greater than this critical value or if the $p$-value is less than $\alpha$. To implement the subsampling technique, a choice of block length $b$ should be made. Whang and kim (2003) recommended that a number of block lengths from an equally spaced grid in the interval of $\left[2.5 T^{0.3}, 3.5 T^{0.6}\right]$ be taken. However, they find that the size and power properties of their test are not sensitive to the choice of block length. ${ }^{8}$

\section{DATA AND EMPIRICAL RESULTS}

To conduct our empirical analysis, we specifically study the following MENA equity markets: Bahrain, Egypt, Jordan, Kuwait, Lebanon, Morocco, Oman, Qatar, Tunisia, UAE and then the group of GCC markets and the group of all Arab markets. The $\mathrm{MSCl}$ Gulf Cooperation Council (GCC) Countries index represents the universe of companies in 6 Gulf Cooperation Council equity markets (Bahrain, Kuwait, Oman, Qatar, Saudi Arabia and United Arab Emirates). The $\mathrm{MSCl}$ Arabian Markets Index covers 11 equity markets. The index aims to represent the universe of companies in the $\mathrm{MSCl} \mathrm{GCC}$ countries index plus Jordan, Egypt, Morocco, Tunisia and Lebanon. All the data is obtained from the Morgan Stanley database on emerging markets. The sample data are daily returns of stock market indices and they cover the sample period from May 1, 2005 to April 26, 2012. We analyze the continuously compounded rate of return, $r(t)=\log (S(t) / S(t-1))$, where $S(t)$ denotes the stock index in day $t$. Such transformation implements an effective detrending of the series. 
Table 1 summarizes the statistical properties of the returns: we show the first four moments, the autocorrelation coefficient at lag one and the Ljung and Box test statistics for autocorrelation in returns and squared returns. All series exhibit some positive and negative mean returns and high variability as indicated by the standard deviation. Egypt, UAE and Qatar are the most volatility market within the MENA region. The series exhibit significant level of skewness and kurtosis. The negative skewness implies that the returns are flatter to the left compared to the normal distribution. The kurtosis reported indicates that the return distribution have sharp peaks compared to a normal distribution. The Jarque-Bera Statistics for testing normality confirm the significant non-normality of returns. Considering the autocorrelation of returns, at lag one the AraMarket and Lebanon have the highest coefficients and are significant at the $5 \%$ level. In the table, we further observe two stylized facts about return series that has universal validity, as documented in the survey by Pagan (1996). The first stylized fact is nonnormality of the unconditional distribution of returns in the form of leptokurtosis. This phenomenon has been termed fat tails. The second stylized fact is that the volatility of returns is time varying. This dependence is indicated by the significant Ljung-Box $Q(20)$ test statistics showing strong autocorrelation in squared returns.

Table 2 includes the results of applying the unit root tests of Saikkonen and Lütkepohl (2002) and Lanne et

Table 2: Unit Root Tests in the Level of Stock Market Returns

\begin{tabular}{|c|c|c|c|c|c|c|}
\hline Country & Shift function & Test statistic & Shift date & Country & Shift function & Test statistic \\
\hline \hline Bahrain & $f_{t}^{(1)}$ & -2.453 & $01 / 26 / 2009$ & Lebanon & $f_{t}^{(1)}$ & -2.950 \\
\hline Egypt & $f_{t}^{(1)}$ & -4.055 & $10 / 08 / 2008$ & Morocco & $f_{t}^{(1)}$ & -4.177 \\
\hline Jordan & $f_{t}^{(1)}$ & -6.214 & $03 / 06 / 2006$ & Oman & $f_{t}^{(1)}$ & -3.125 \\
\hline Kuwait & $f_{t}^{(1)}$ & -4.376 & $11 / 17 / 2008$ & Qatar & $f_{t}^{(1)}$ & -4.308 \\
\hline Tunisia & $f_{t}^{(1)}$ & -4.801 & $05 / 13 / 2008$ & GCC & $f_{t}^{(1)}$ & -3.605 \\
\hline UAE & $f_{t}^{(1)}$ & -3.985 & $12 / 09 / 2009$ & ArabMarket & $f_{t}^{(1)}$ & -3.302 \\
\hline
\end{tabular}

Notes: Critical values are based on Lanne et al. (2001). They are as follow: $-3.48,-2.88$, and -2.58 for $1 \%, 5 \%$ and $10 \%$, significance levels, respectively. The shift date is estimated by minimizing the objective function. Lags included in the regression are: Bahrain 2, Egypt 2, Jordan 2, Kuwait 4, Lebanon 2 , Morocco 2 , Oman 4 , Qatar 2, Tunisia 2, UAE 1, GCC 3, and ArabMarket 4.

Table 3: Critical Values for Wright's R1, R2, and S1

\begin{tabular}{|c|c|c|}
\hline$k$ & $T=1801$ & $10 \%$ \\
\hline$R 1$ & $5 \%$ & -1.6611 .576 \\
\hline 2 & & -1.6421 .589 \\
\hline 5 & -1.9591 .869 & -1.6731 .578 \\
\hline 10 & -1.9611 .868 & -1.6911 .543 \\
\hline$R 2$ & -2.0021 .955 & -1.6811 .533 \\
\hline 2 & & -1.6691 .617 \\
\hline 5 & -1.9891 .852 & -1.7201 .534 \\
\hline 10 & -1.9811 .886 & -1.7251 .530 \\
\hline 21 & -1.9271 .944 & -1.6621 .620 \\
\hline 5 & & -1.9881 .850 \\
\hline
\end{tabular}

Notes: The critical values were simulated with 10,000 replications in each case. The $5 \%(10 \%)$ critical values represent the $2.5^{\text {th }}\left(5^{\text {th }}\right)$ and $97.5^{\text {th }}\left(95^{\text {th }}\right)$ percentiles of the simulated distributions of the statistic. 
al. (2002) with the shift dummy function $f_{t}^{(1)}$. In executing the test it is necessary to decide on the AR order and the shift date $T_{B}$. If the latter quantity is known, the desired shift function may be included, and the AR order may be chosen in the usual way for a model in levels with the help of order selection criteria, sequential tests, and model checking tools. If the break date is unknown, Lanne, Lütkepohl \& Saikkonen (2003) have recommended, on the basis of simulation results, choosing a reasonably large AR order in a first step and then picking the break date. In this first step, choosing a shift dummy as shift function is recommended. Usually the choice of the break date will not be critical if it is not totally unreasonable. Or to say, the unit root test is not sensitive to slight misspecification of the break date.

In executing the test statistic, it is helpful to map the series with the estimated deterministic terms, the adjusted series as well as the estimated shift function. Also, it is recommended to map an objective function, which is minimized in estimating the deterministic parameters. We have tried with different shift functions. The results are not plotted to save space, but only provide the test statistics for the shift dummy function. In each case, the break date is estimated by a grid search instead of setting it a priori. We also considered a large number of lags (10 lags), but then looked at Akaike Information (1974), Hannan and Quinn (1979), and Schwarz (1978) criteria, we were able to determine the following lags for each series: Bahrain 2, Egypt 2, Jordan 2, Kuwait 4, Lebanon 2, Morocco 2, Oman 4, Qatar 2, Tunisia 2, UAE 1, GCC 3, and ArabMarket 4.

The null hypothesis of nonstationarity is rejected for all forms of the shift function and clearly, all equity returns proved to be integrated of order zero. Also, Table 2 provides the possible break in the return series, with the shift function providing similar levels of breaks in all series. Surprisingly, all the MENA equity markets show the breaks to occur in 2008 and 2009 periods, except that for Jordan, where the break takes place in 2006.

Table 4 reports the individual test statistics $\left(R_{1}, R_{2}\right.$, $S_{1}$ ) for the whole sample as detailed in Wright (2000). In making inferential decisions using these statistics, we reject the null of RWH (or martingale) if there are more than two rejections at any of three levels of significance we have considered $(1 \%, 5 \%$ and $10 \%)$. Under the null hypothesis the series follows a random walk and the variance ratios are expected to be equal to one. The tests are implemented for different holding periods, k. In particular, we implement the tests given values of $k=2,5$ and 10 days respectively. As suggested by Deo and Richardson (2003) the choice of $k$ is relatively short. Following Hoque et al. (2007) we reject the EMH in the case of two or more rejections at the usual level of statistical significance. Table 4 indicates that for most countries considered, the null hypothesis is rejected for all holding periods, except for Kuwait, Lebanon and Tunisia. In case of Kuwait, the table shows no rejections for the three tests and almost all holding periods. For Lebanon, we cannot reject the null hypothesis only according to R1 and for Tunisia, $\mathrm{S} 1$ does not reject the null for all $\mathrm{k}$ holding periods. It is apparent that the null of RWH is rejected for all the MENA emerging markets at the $5 \%$ level of significance. It should be noted that all test statistics $\left(R_{1}, R_{2}\right.$, and $\left.S_{1}\right)$ reported give rise to fairly consistent inferences with the exception of Kuwait, Lebanon and Tunisia.

Table 5 reports the $p$-values for the joint tests of Wang and Kim (2003), and individuals tests of Chow and Denning (1993), CD1 and CD2. Table 5 considers the full sample with the corresponding $k$ holding periods. The results of the Wang and Kim (2003) tests show rejections of the random walk hypothesis for almost all the MENA equity markets, as the $p$-values are less than the $1 \%$. Bahrain and Kuwait show significance at the $10 \%$ significance level, while Jordan does not reject the RWH at any significant levels. Oman also has similar results as those of Kuwait and Bahrain. The ArabMarket and GCC both show strong evidence of rejection to the RWH according to the $p$ values. Using the Chow and Denning (1993) test statistics, we observe that Kuwait and Bahrain again do not reject the null hypothesis at the $10 \%$ significance levels and Oman accept the null as represented by CD2 not CD1. For the rest of the countries, it is apparent that both test statistics provide similar results, and confirm those obtained from Table 4.

Tables 6 and 7 present Wright's (2000) variance ratio test with a comparative analysis of different levels of efficiency in different sub-periods. The results shows remarkable differences when the tests are performed on the sub-periods, revealing how these markets have evolved in terms of efficiency. The results for the first sub-period depicts that the random walk hypothesis is rejected by $\mathrm{R} 1, \mathrm{R} 2$ and $\mathrm{S} 1$ for most of the markets at every lag, except for those of Jordan and Lebanon. Comparative analysis of $\mathrm{R} 1, \mathrm{R} 2$ and $\mathrm{S} 1$ reflects that the $\mathrm{S} 1$ results display less rejection of the random walk hypothesis for more countries, than those obtained by R1 and R2 (i.e., Egypt, Morocco, Kuwait and others) 
Table 4: Individuals Test of Wright (2000), R1, R2, and S3. K is the Holding Period

\begin{tabular}{|c|c|c|c|c|}
\hline Country/Test & $\mathrm{K}$ & R1 & R2 & s1 \\
\hline \multirow[t]{3}{*}{ Bahrain } & 2 & $3.055^{*}$ & $3.878^{*}$ & $4.567^{*}$ \\
\hline & 5 & $3.023^{*}$ & $3.821^{*}$ & $7.161^{*}$ \\
\hline & 10 & $3.072^{\star}$ & $3.779^{*}$ & $10.786^{*}$ \\
\hline \multirow[t]{3}{*}{ Egypt } & 2 & $3.508^{*}$ & $3.963^{*}$ & $2.260^{*}$ \\
\hline & 5 & $4.155^{*}$ & $4.636^{*}$ & $3.120^{*}$ \\
\hline & 10 & $2.601^{*}$ & $3.075^{*}$ & $3.425^{\star}$ \\
\hline \multirow[t]{3}{*}{ Jordan } & 2 & $2.444^{*}$ & $2.585^{*}$ & 1.977) \\
\hline & 5 & $2.343^{*}$ & $2.364^{*}$ & $2.123^{*}$ \\
\hline & 10 & $2.402^{*}$ & 1.887 & $2.730^{*}$ \\
\hline \multirow[t]{3}{*}{ Kuwait } & 2 & 1.592 & 1.914 & $0.565)$ \\
\hline & 5 & 1.828) & 2.245 & 0.077 \\
\hline & 10 & 1.699 & 1.796 & 1.394 \\
\hline \multirow[t]{3}{*}{ Lebanon } & 2 & $3.051^{*}$ & $4.029^{*}$ & $2.118^{*}$ \\
\hline & 5 & 1.632 & $2.095^{*}$ & $2.226^{*}$ \\
\hline & 10 & 1.671 & $2.269^{*}$ & $2.674^{*}$ \\
\hline \multirow[t]{3}{*}{ Morocco } & 2 & $6.722^{*}$ & $7.758^{*}$ & $4.614^{*}$ \\
\hline & 5 & $4.623^{*}$ & $5.156^{*}$ & $3.413^{*}$ \\
\hline & 10 & $3.024^{*}$ & $2.971^{*}$ & $2.613^{*}$ \\
\hline \multirow[t]{3}{*}{ Oman } & 2 & $5.956^{*}$ & $5.592^{*}$ & $4.237^{*}$ \\
\hline & 5 & $6.478^{*}$ & $5.937^{*}$ & $4.685^{\star}$ \\
\hline & 10 & $5.566^{*}$ & $4.721^{*}$ & $5.782^{*}$ \\
\hline \multirow[t]{3}{*}{ Qatar } & 2 & $2.487^{*}$ & $2.688^{*}$ & 1.365 \\
\hline & 5 & $4.276^{*}$ & $4.288^{*}$ & $2.722^{*}$ \\
\hline & 10 & $4.491^{*}$ & $4.220^{*}$ & $3.059^{*}$ \\
\hline \multirow[t]{3}{*}{ Tunisia } & 2 & $3.817^{*}$ & $4.630^{*}$ & 1.130 \\
\hline & 5 & $3.038^{*}$ & $3.566^{*}$ & 1.194) \\
\hline & 10 & 1.783 & 1.744 & 1.160 \\
\hline \multirow[t]{3}{*}{ UAE } & 2 & $4.290^{*}$ & $4.637^{*}$ & 1.271 \\
\hline & 5 & $6.006^{*}$ & $6.051^{*}$ & $2.518^{*}$ \\
\hline & 10 & $5.689^{*}$ & $5.589^{*}$ & $3.260^{*}$ \\
\hline \multirow[t]{3}{*}{ GCC } & 2 & $3.749^{*}$ & $3.740^{*}$ & $2.680^{*}$ \\
\hline & 5 & $6.105^{*}$ & $5.867^{*}$ & $5.906^{*}$ \\
\hline & 10 & $6.435^{*}$ & $5.860^{*}$ & $6.992^{*}$ \\
\hline \multirow[t]{3}{*}{ ArabMarket } & 2 & $4.717^{*}$ & $4.541^{*}$ & $4.002^{*}$ \\
\hline & 5 & $6.949^{*}$ & $6.702^{*}$ & $6.353^{*}$ \\
\hline & 10 & $6.790^{*}$ & $6.328^{*}$ & $6.312^{*}$ \\
\hline
\end{tabular}


Table 5: Joint Test Results of Wang and Kim (2003), and Individuals Tests of Chow and Denning (1993), CD1 and CD2

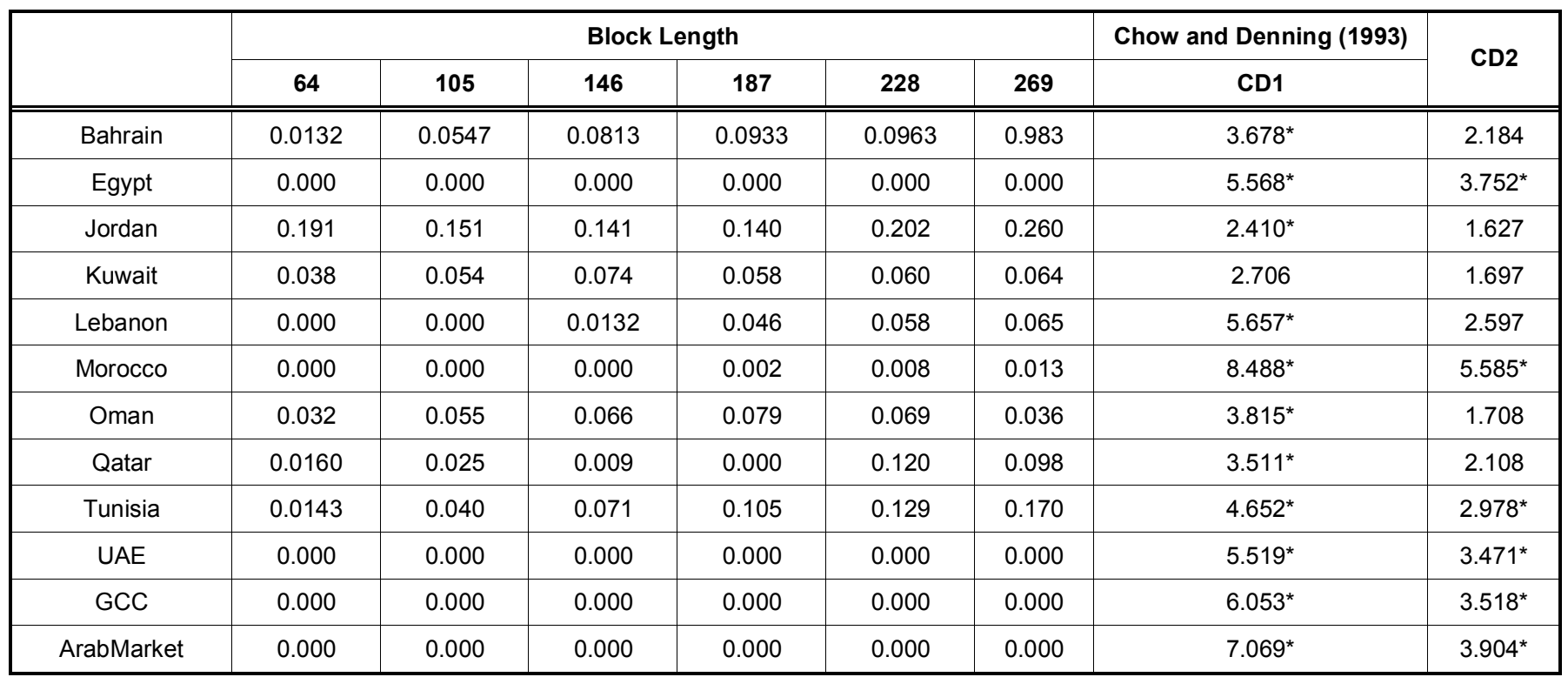

Notes: Following Wang and Kim (2003), block lengths are chosen from an equally spaced grid in the interval $\left[2.5 T^{0.3}, 3.5 T^{0.6}\right]$. The critical values for Chow and Denning test are $2.114,2.387$, and 2.934 at the $10 \%, 5 \%$, and $1 \%$ significance levels.

Table 6: Individuals Test of Wright (2000), R1, R2, and S3. K is the Holding Period Sub-Sample One

\begin{tabular}{|c|c|c|c|c|}
\hline Country/Test & $\mathbf{K}$ & R1 & $\mathbf{R 2}$ & S1 \\
\hline \multirow[t]{2}{*}{ Bahrain } & 2 & $2.719^{*}$ & $3.130^{*}$ & $3.693^{*}$ \\
\hline & 10 & $2.532^{*}$ & $2.984^{*}$ & $8.522^{*}$ \\
\hline \multirow[t]{2}{*}{ Egypt } & 2 & $2.768^{*}$ & $3.331^{*}$ & 1.084 \\
\hline & 10 & 1.995 & $2.413^{*}$ & 1.308 \\
\hline \multirow[t]{3}{*}{ Jordan } & 2 & 0.356 & 0.202 & -0.538 \\
\hline & 5 & -0.810 & -0.975 & -0.743 \\
\hline & 10 & -0.332 & -0.460 & -0.826 \\
\hline \multirow[t]{3}{*}{ Lebanon } & 2 & $2.845^{*}$ & $3.753^{*}$ & $2.046^{*}$ \\
\hline & 5 & 1.432 & $2.036^{*}$ & 1.040 \\
\hline & 10 & 1.723 & $2.446^{*}$ & 0.934 \\
\hline \multirow[t]{3}{*}{ Morocco } & 2 & $6.489^{*}$ & $7.363^{*}$ & $4.925^{*}$ \\
\hline & 5 & $4.844^{*}$ & $5.350^{*}$ & $4.031^{*}$ \\
\hline & 10 & $3.386^{*}$ & $3.386^{*}$ & $3.317^{*}$ \\
\hline \multirow[t]{2}{*}{ Oman } & 2 & $4.924^{*}$ & $4.784^{*}$ & $3.484^{*}$ \\
\hline & 5 & $4.723^{*}$ & $4.398^{*}$ & $3.236^{*}$ \\
\hline
\end{tabular}




\begin{tabular}{|c|c|c|c|c|}
\hline Country/Test & $\mathbf{K}$ & R1 & R2 & s1 \\
\hline \multirow[t]{3}{*}{ Qatar } & 2 & $2.545^{\star}$ & $2.416^{*}$ & 1.891 \\
\hline & 5 & $3.849^{*}$ & $3.614^{*}$ & $3.242^{*}$ \\
\hline & 10 & $4.315^{\star}$ & $3.734^{*}$ & $3.651^{*}$ \\
\hline \multirow[t]{3}{*}{ Tunisia } & 2 & $3.344^{*}$ & $3.734^{*}$ & 1.766) \\
\hline & 5 & $3.234^{*}$ & $3.526^{*}$ & 2.012 \\
\hline & 10 & $2.412^{*}$ & $2.392^{*}$ & 1.934 \\
\hline \multirow[t]{3}{*}{ UAE } & 2 & $4.040^{*}$ & $4.357^{*}$ & 1.106 \\
\hline & 5 & $5.865^{\star}$ & $5.843^{*}$ & $2.532^{*}$ \\
\hline & 10 & $5.710^{*}$ & $5.520^{*}$ & $3.352^{*}$ \\
\hline \multirow[t]{3}{*}{ GCC } & 2 & $3.598^{*}$ & $3.443^{*}$ & $3.043^{*}$ \\
\hline & 5 & $5.777^{*}$ & $5.372^{*}$ & $6.112^{*}$ \\
\hline & 10 & $6.415^{*}$ & $5.593^{*}$ & $7.412^{*}$ \\
\hline \multirow[t]{3}{*}{ ArabMarket } & 2 & $4.129^{*}$ & $3.998^{*}$ & $3.929^{*}$ \\
\hline & 5 & $6.070^{*}$ & $5.840^{*}$ & $6.294^{*}$ \\
\hline & 10 & $6.170^{*}$ & $5.651^{*}$ & $6.648^{*}$ \\
\hline
\end{tabular}

Notes: The table provides the individuals test of Wright (2000), R1, R2, and S3. K is the holding period. * indicates significance at the $5 \%$ level.

Table 7: Individuals Test of Wright (2000), R1, R2, and S3. K is the Holding Period Sub-Sample Two

\begin{tabular}{|c|c|c|c|c|}
\hline Country/Test & $\mathrm{K}$ & R1 & R2 & S1 \\
\hline \multirow[t]{3}{*}{ Bahrain } & 2 & 1.009 & 1.954 & $2.668^{*}$ \\
\hline & 5 & 1.558 & $2.484^{*}$ & $4.788^{*}$ \\
\hline & 10 & 1.443 & 2.111 & $6.565^{\star}$ \\
\hline \multirow[t]{3}{*}{ Egypt } & 2 & 2.056 & 1.880 & $2.372^{*}$ \\
\hline & 5 & 1.474 & 1.559 & $2.827^{\star}$ \\
\hline & 10 & 0.958 & 1.256 & $4.110^{*}$ \\
\hline \multirow[t]{3}{*}{ Jordan } & 2 & $2.233^{*}$ & $2.540^{*}$ & $2.355^{\star}$ \\
\hline & 5 & $2.662^{*}$ & $3.017^{*}$ & $2.570^{*}$ \\
\hline & 10 & $2.522^{*}$ & $2.160^{*}$ & $3.299^{*}$ \\
\hline \multirow[t]{3}{*}{ Kuwait } & 2 & -0.482 & -0.372 & -1.33 \\
\hline & 5 & -0.371 & -0.309 & -1.887 \\
\hline & 10 & -0.510 & -0.593 & -1.666 \\
\hline \multirow[t]{3}{*}{ Lebanon } & 2 & 0.956 & 1.166 & 0.671 \\
\hline & 5 & 0.214 & $-0.097)$ & $2.452^{\star}$ \\
\hline & 10 & -0.682 & -1.173 & $3.248^{\star}$ \\
\hline \multirow[t]{3}{*}{ Morocco } & 2 & $2.144^{*}$ & $2.480^{*}$ & 0.761 \\
\hline & 5 & 0.540 & $0.438)$ & -0.098 \\
\hline & 10 & -0.418 & -0.758 & -0.437 \\
\hline \multirow[t]{3}{*}{ Oman } & 2 & $3.382^{*}$ & $2.800^{\star}$ & $2.372^{\star}$ \\
\hline & 5 & $4.874^{*}$ & $4.501^{*}$ & $3.577^{\star}$ \\
\hline & 10 & $4.188^{*}$ & $3.970^{*}$ & $3.367^{*}$ \\
\hline
\end{tabular}


(Table 7). Continued.

\begin{tabular}{|c|c|c|c|c|}
\hline Country/Test & $\mathbf{K}$ & R1 & R2 & S1 \\
\hline \multirow[t]{3}{*}{ Qatar } & 2 & -0.144 & 0.912 & -0.551 \\
\hline & 5 & 1.393 & $2.274^{*}$ & -0.218 \\
\hline & 10 & 0.686 & 1.291 & -0.185 \\
\hline \multirow[t]{3}{*}{ Tunisia } & 2 & 1.882 & 2.701 & -0.407 \\
\hline & 5 & 0.780 & 1.253 & -0.595 \\
\hline & 10 & -0.204 & -0.246 & -0.555 \\
\hline \multirow[t]{3}{*}{ UAE } & 2 & 1.548 & 1.803 & 0.648 \\
\hline & 5 & 1.012 & 1.175 & 1.480 \\
\hline & 10 & 0.238 & 0.238 & -0.115 \\
\hline \multirow[t]{3}{*}{ GCC } & 2 & 0.964 & 1.124 & 0.134 \\
\hline & 5 & 1.842 & 1.926 & 1.307 \\
\hline & 10 & 1.187 & 1.057 & 1.280 \\
\hline \multirow[t]{3}{*}{ ArabMarket } & 2 & $2.212^{*}$ & $2.010^{*}$ & 1.208 \\
\hline & 5 & $3.223^{*}$ & $3.026^{\star}$ & 1.863 \\
\hline & 10 & $2.463^{*}$ & $2.164^{*}$ & 1.211 \\
\hline
\end{tabular}

Notes: The table provides the individuals test of Wright (2000), R1, R2, and S3. K is the holding period. * indicates significance at the $5 \%$ level.

indicating that these countries become efficient in the first sub-period. Comparing those results to Table 6, we observe that the 2nd sub-period shows improvement for most markets except for Oman and Jordan. These findings may be due to the small size of these markets compared to other major MENA equity markets. Finally, S1 rejects the random walk hypothesis for Bahrain, Egypt, Jordan and Oman, as compared to R1 and R2, which provide more evidence of market efficiency in the second sub-period.

Tables 8 and 9 again report the $p$-values for the joint tests of Wang and Kim (2003), and individuals tests of Chow and Denning (1993), CD1 and CD2. Table 8 considers the first sub-sample with the corresponding $\mathrm{k}$ holding periods. The results of the Wang and Kim (2003) tests show rejections of the random walk hypothesis for almost all the MENA equity markets, as the $p$-values are less than the $1 \%$, except for Jordan and Tunisia. Oman is another exception, but shows rejection again at the $5 \%$ level. Those results fall in line with those obtained from Table $\mathbf{4}$ for the whole sample. Using the Chow and Denning (1993) test statistics, we observe that Bahrain, Jordan and Qatar do not reject the null hypothesis at the $5 \%$ significance levels. Comparing those results to the second subsample in Table 9, we find that most countries do not reject the random walk hypothesis as implied by the joint tests of Wang and Kim (2003) since all the pvalues are larger than $5 \%$, except for Qatar, that reject the random walk hypothesis. Considering the results of Chow and Denning (1993), most countries evolve to become efficient, since only few countries reject the random walk hypothesis at the $5 \%$. The results obtained from Tables 8 and 9 fall in line with those confirmed according to Wright's (2000) tests.

\section{CONCLUSION AND IMPLICATIONS}

This paper investigates whether a group of MENA equity markets returns follow a martingale process and whether a structural break like the financial crisis of 2008 had any impact on the efficient market hypothesis of these markets. In this study, we apply multiple variance ratio tests based on the wild bootstrap and signs, in addition to the conventional Chow-Denning test. Also we apply some unit roots tests with regime shifts. The findings indicate that the equity markets of the MENA region appear to be evolving in the right direction, especially during the last five to ten years. However, during the earlier sub-period, these markets experienced significant positive autocorrelation (persistence) in returns. Another notable finding concerns how these emerging markets have been affected by the impact of the current financial crisis, which has paralyzed many developed economies and left great devastation. The last sub-period results for the MENA region clearly provide support that these markets may have been approaching a state of being fairly weak-form efficient. 
Table 8: Joint Test Results of Wang and Kim (2003), and Individuals Tests of Chow and Denning (1993), CD1 and CD2 for the First Period (Sub-Sample One)

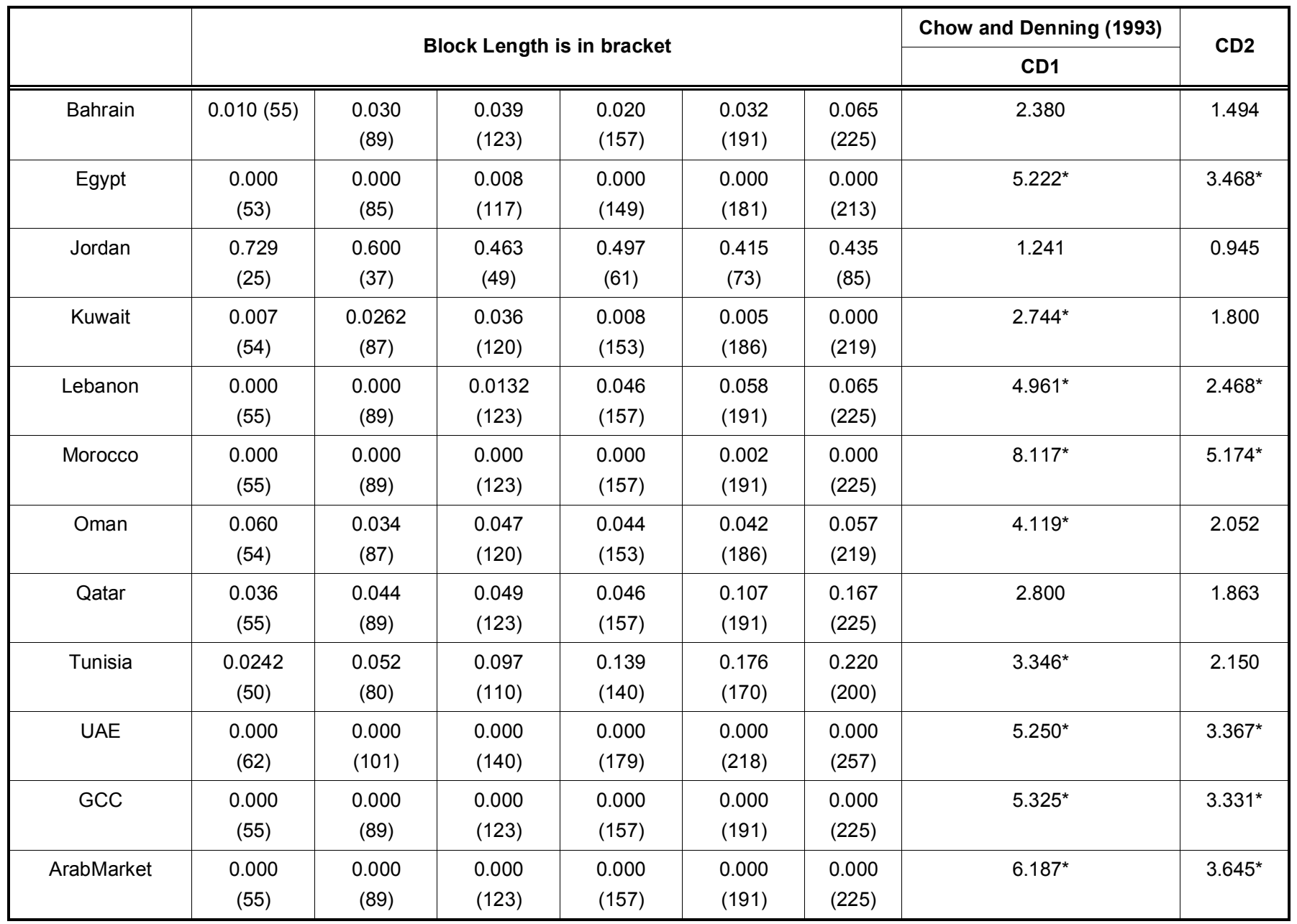

Notes: Following Wang and Kim (2003), block lengths are chosen from an equally spaced grid in the interval $\left[2.5 T^{0.3}, 3.5 T^{0.6}\right]$. The critical values for Chow and Denning test are $2.114,2.387$, and 2.934 at the $10 \%, 5 \%$, and $1 \%$ significance levels. The first period correspond to the number of observations obtained from Lanne et al. (2001) tests. * indicates significance at the $5 \%$ level.

Table 9: Joint Test Results of Wang and Kim (2003), and Individuals Tests of Chow and Denning (1993), CD1 and CD2 for the Second Period (Sub-Sample Two)

\begin{tabular}{|c|c|c|c|c|c|c|c|c|}
\hline \multirow[b]{3}{*}{ Bahrain } & \multirow{2}{*}{\multicolumn{6}{|c|}{ Block Length is in bracket }} & \multirow{3}{*}{$\begin{array}{c}\text { Chow and Denning (1993) } \\
\text { CD1 } \\
5.647^{*}\end{array}$} & \multirow{3}{*}{$\begin{array}{c}\text { CD2 } \\
2.578^{*}\end{array}$} \\
\hline & & & & & & & & \\
\hline & $\begin{array}{c}0.000 \\
(34)\end{array}$ & $\begin{array}{c}0.000 \\
(52)\end{array}$ & $\begin{array}{c}0.000 \\
(70)\end{array}$ & $\begin{array}{c}0.146 \\
(88)\end{array}$ & $\begin{array}{l}0.234 \\
(106)\end{array}$ & $\begin{array}{l}0.281 \\
(124)\end{array}$ & & \\
\hline Egypt & $\begin{array}{c}0.0018 \\
(36)\end{array}$ & $\begin{array}{c}0.021 \\
(56)\end{array}$ & $\begin{array}{c}0.091 \\
(76)\end{array}$ & $\begin{array}{c}0.141 \\
(96)\end{array}$ & $\begin{array}{l}0.199 \\
(116)\end{array}$ & $\begin{array}{l}0.230 \\
(136)\end{array}$ & 2.343 & 1.483 \\
\hline Kuwait & $\begin{array}{c}0.665 \\
(35)\end{array}$ & $\begin{array}{c}0.510 \\
(54)\end{array}$ & $\begin{array}{c}0.522 \\
(73)\end{array}$ & $\begin{array}{c}0.575 \\
(92)\end{array}$ & $\begin{array}{l}0.566 \\
(111)\end{array}$ & $\begin{array}{l}0.585 \\
(130)\end{array}$ & 0.808 & 0.633 \\
\hline Lebanon & $\begin{array}{c}0.004 \\
(34)\end{array}$ & $\begin{array}{c}0.004 \\
(52)\end{array}$ & $\begin{array}{c}0.000 \\
(70)\end{array}$ & $\begin{array}{c}0.041 \\
(88)\end{array}$ & $\begin{array}{l}0.048 \\
(106)\end{array}$ & $\begin{array}{l}0.114 \\
(124)\end{array}$ & 2.054 & 1.368 \\
\hline
\end{tabular}


(Table 9). Continued.

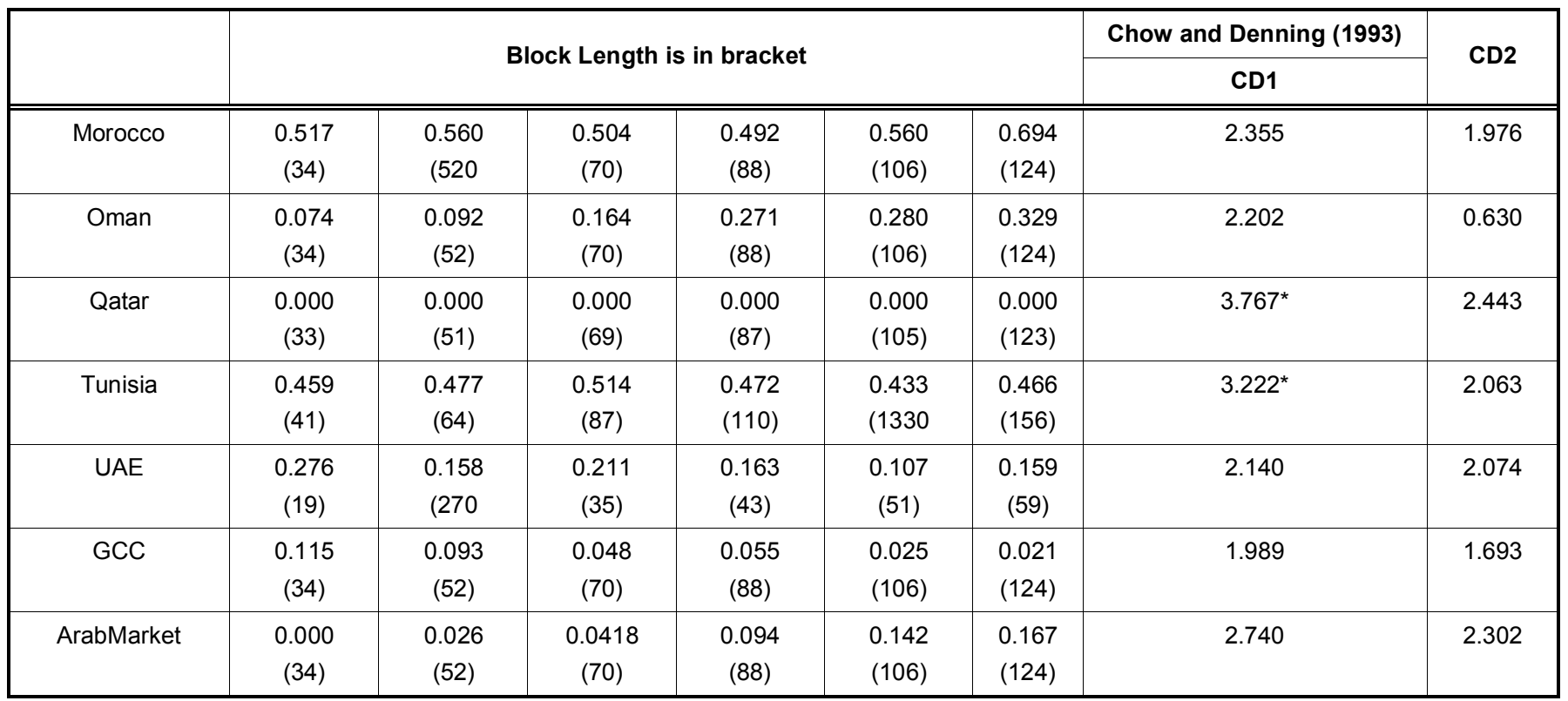

Notes: Following Wang and Kim (2003), block lengths are chosen from an equally spaced grid in the interval $\left[2.5 T^{0.3}, 3.5 T^{0.6}\right.$ ] . The critical values for Chow and Denning test are $2.114,2.387$, and 2.934 at the $10 \%, 5 \%$, and $1 \%$ significance levels. * indicates significance at the $5 \%$ level.

Our results are related to some events and changes that have been taking place in the MENA region in the past ten years. For example, a strengthening global demand for oil in the past few years fueled economic growth in the MENA's oil exporting countries, despite the waves of violence and insecurity overshadowing the MENA's oil importing countries. To secure a robust private sector performance, many MENA countries are focusing on social reforms and preservation their positions among other countries. For example, the United Arab Emirates economy finally recovered from the Dubai crisis of 2009 due to the promising performance of real estate, tourism and trade sectors that were boosted by Emirates winning the right to host the World Expo 2020. On the other hand, the oilimporting countries were striving to resolve their political and economic problems. Egypt for example, started a series of structural economic reforms that was followed by a period of political stability that had a positive impact on its equity markets. Jordan at the same time was undergoing some instabilities but was trying to install some basic economic principles required by the International Monetary Fund (IMF) under a new loan agreement. All these events had their impact on the performance of MENA equity markets after the financial crisis.

Other benefits could emerge from the results of our study. For example, testing for market efficiency in these markets has an important bearing on the pricing of equity derivatives in MENA region. Options in the
MENA region are still limited to over-the-counter trading, but the market appetite for the risk-return profile of MENA-based derivatives is strong. As trading in MENA equity derivatives strengthens, it is important that the pricing models used include an assumption about long-range dependence. Second, our results would be useful for investors employing asset allocation strategies and may demonstrate that, despite their infancy, MENA equity prices exhibit characteristics akin with more mature markets.

Finally, an important implication of this study is that it highlights the relative increase in efficiency, which is an important ingredient for these countries if they wish to foster their economic growth and welfare. Because these markets are facing many challenges and problems, there is considerable room for other types of economic or political studies that explore these factors and might be the causes of efficiency or inefficiency.

\section{REFERENCES}

Akaike, H., (1974) A new look at the statistical model identification", IEEE Transactions on Automatic Control 19 (6): 716-723. https://doi.org/10.1109/TAC.1974.1100705

Abraham, A., Seyyed, F. and Alsakran, S. (2002). "Testing the random walk behavior and efficiency of the Gulf stock markets." The Financial Review, Vol.37: 469-480. https://doi.org/10.1111/0732-8516.00008

Aggarwal, R., C. Inclan and R. Leal. (1999). "Volatility in emerging markets." Journal of Financial and Quantitative Analsysis, 3335.

https://doi.org/10.2307/2676245 
Al-Loughani, N. E. (1995). "Random walk in thinly traded stock markets: the case of Kuwait". Arab Journal of Administrative Sciences, Vol. 3: 189-209.

Al-Loughani, N. E., I. A. Moosa. (1997). "Testing the efficiency of an emerging stock market using trading rules: the case of Kuwait." Working Paper Series Number 1. Kuwait: College of Administrative Science, Kuwait University.

Appiah-Kusi, J. \& Menyah K. (2003). Return predictability in African stock markets. Review of Financial Economics, 12, 247-270. https://doi.org/10.1016/S1058-3300(02)00073-3

Bailey, W. and Y.P. Chung. (1996). "Exchange rate fluctuation, political risk, and stock market returns: some evidence from an emerging market." Journal of Financial and Quantitative Analysis, Vol. 30: 541-561. https://doi.org/10.2307/2331276

Bekaert, G., and Harvey, C.R. (1995). Time-varying world market integration. Journal of Finance, 50, 403-444. https://doi.org/10.1111/j.1540-6261.1995.tb04790.x

Bekaert, G., and Harvey, C.R. (1997). Emerging equity market volatility. Journal of Financial Economics, 43, 29-78. https://doi.org/10.1016/S0304-405X(96)00889-6

Bollerslev, T. and H.O.Mikkelsen. (1996). "Modelling and Pricing Long-Memory in Stock Market Volatility." Journal of Econometrics, Vol.73: 151-184. https://doi.org/10.1016/0304-4076(95)01736-4

Bulter, K. C., Malaikah, S.J. (1992). "Efficiency and inefficiency in thinly traded stock markets: Kuwait and Saudi Arabia." Journal of Banking and Finance, Vol.16:197-210. https://doi.org/10.1016/0378-4266(92)90085-E

Brooks, R. (2007). Power ARCH modelling of the volatility of emerging equity markets. Emerging Markets Review, 8, 124133.

https://doi.org/10.1016/j.ememar.2007.01.002

Chen, W.W., Deo, R.S., (2006). The variance ratio statistic at large horizons. Econometric Theory 22, 206-234. https://doi.org/10.1017/s0266466606060099

Choudhry, T. (1996) Stock Market Volatility and Crash of 1987: Evidence from Six Emerging Countries. Journal of International Money and Finance 15:6, 969-981. https://doi.org/10.1016/S0261-5606(96)00036-8

Chow, K.V., Denning, K.C., (1993). A simple multiple variance ratio test. Journal of Econometrics 58, 385-401. https://doi.org/10.1016/0304-4076(93)90051-6

Chow, K.V., Denning, K.C., Ferris, S. and Noronha, G., (1995). Longterm and Short-term price memory in the stock market. Economics Letters 49, 287-293. https://doi.org/10.1016/0165-1765(95)00690-H

Claessens, S., Dasgupta, S., \& Glen, J. (1995). Return behavior in emerging stock markets. World Bank Economic Review, 9, 131-152. https://doi.org/10.1093/wber/9.1.131

Darrat, A. F. and Pennathur, A. (2002). "Are the Arab Maghreb countries really integratable? Some evidence from the theory of cointegrated systems." Review of Financial Economics, Vol.11: 79-90. https://doi.org/10.1016/S1059-0560(02)00105-3

Darat, A. F., \& Hakim, S. R. (1997). "Price linkages, efficiency, and integration of emerging stock markets in the Middle East." Paper presented at conference on Regional Trade, Finance and Labor Markets in Transition. Beirut, 7-9 October.

Darrat, A. F. and Pennathur, A. (2002). Are the Arab Maghreb countries really integratable? some evidence from the theory of cointegrated systems. Review of Financial Economics, 11, 79-90. https://doi.org/10.1016/S1059-0560(02)00105-3

De Santis, G. and Imrohoroglu, S. (1997). Stock returns and volatility in emerging financial markets. Journal of International Money and Finance, 16, 561-579. https://doi.org/10.1016/S0261-5606(97)00020-X
Deo, R.S., Richardson, M., (2003). On the asymptotic power of the variance ratio test. Econometric Theory 19, 231-239. https://doi.org/10.1017/s0266466603192018

Domowitz, I., Glen, J., and Madhavan, A. (1998). "International cross-listing and order flow migration: evidence from an emerging market." Journal of Finance, Vol. 53: 2001-2027. https://doi.org/10.1111/0022-1082.00081

El Erian, M., Kumar,M. (1995). "Emerging equity markets in Middle Eastern countries." in: development of financial markets in the Arab Countries, Iran and Turkey (Cairo: Economic Research Forum for the Arab Countries, Iran and Turkey) 129-75. https://doi.org/10.2307/3867575

Errunza, V.R. (1994). "Emerging markets: some new concepts." Journal of Portfolio Management, Vol. 20: 82-87. https://doi.org/10.3905/jpm.1994.82

Errunza, V.R. (1983). "Emerging Markets: a New Opportunity for Improving Global Portfolio Performance." Financial Analyst Journal, 51-58 https://doi.org/10.2469/faj.v39.n5.51

Ghysels, E. \& Cherkaoui, M. (2003). Emerging markets and trading costs: lessons from Casablanca. Journal of Empirical Finance, 10, 169-198. https://doi.org/10.1016/S0927-5398(02)00026-9

Hammoudeh, S. and Li, H. (2008). Sudden changes in volatility in emerging markets: The case of Gulf Arab stock markets. International Review of Financial Analysis, 17, 47-63. https://doi.org/10.1016/j.irfa.2005.01.002

Hannan, E. J., and B. G. Quinn (1979), The Determination of the Order of an Autoregression, Journal of the Royal Statistical Society, B, 41, 190-195.

Harvey, C.R. (1995). "Predictable risk and returns in emerging markets." Review of Financial Studies, Vol.8: 773 - 816. https://doi.org/10.1093/rfs/8.3.773

Hoque, H.A.A.B., Kim, J.H., Pyun, C.S., (2007). A comparison of variance ratio tests of random walk: a case of Asian emerging stock markets. International Review of Economics and Finance 16, 488-502. https://doi.org/10.1016/j.iref.2006.01.001

Kim, J.H., (2006). Wild bootstrapping variance ratio tests. Economics Letters 92, 38-43. https://doi.org/10.1016/j.econlet.2006.01.007

Lagoarde-Segot, T. and Lucey, B. (2008). Efficiency in emerging markets-Evidence from the MENA region, Journal of International Financial Markets, Institutions and Money, 18, 94-105. https://doi.org/10.1016/j.intfin.2006.06.003

Lagoarde-Segot, T. and Lucey, B. (2007). International portfolio diversification: Is there a role for the Middle East and North Africa? Journal of Multinational Financial Management, 17 401-416.

https://doi.org/10.1016/j.mulfin.2007.01.001

Lagoarde-Segot, T. and Lucey, B. (2008). Efficiency in emerging markets-Evidence from the MENA region, Journal of International Financial Markets, Institutions and Money, 18 94-105. https://doi.org/10.1016/j.intfin.2006.06.003

Lim, k.P, 2009. Weak-form market efficiency and nonlinearity: evidence from Middle East and African stock indices. Applied Economics Letters. $16(5)$ : 519-522. https://doi.org/10.1080/13504850601032032

Lanne, M., Lütkepohl, H. and Saikkonen, P., (2002) Comparison of unit root tests for time series with level shifts, Journal of Time Series Analysis 23, 667-685. https://doi.org/10.1111/1467-9892.00285

Lo, A. and C. MacKinlay. (1989). "The size and Power of the Variance Ratio Test in Finite Samples: a Monte Carlo Investigation." Journal of Econometrics, Vol.40: 203-238. https://doi.org/10.1016/0304-4076(89)90083-3 
Newey, W., and K.West. (1987). "A simple definite, heteroskedasticity and autocorrelation consistent covariance matrix." Econometrica, Vol.55: 277-301. https://doi.org/10.2307/1913610

Nikkinen, J., Omran, M., Sahlström, P. and Äijö, J. (2008). Stock returns and volatility following the September 11 attacks: Evidence from 53 equity markets, International Review of Financial Analysis, 17, 27-46. https://doi.org/10.1016/j.irfa.2006.12.002

Pagan, A., (1996). The econometrics of financial markets, Journal of Empirical Finance 3, 13-102. https://doi.org/10.1016/0927-5398(95)00020-8

Politis, D.N., Romano, J.P., Wolf, M., (1997). Subsampling for heteroskedastic time series. Journal of Econometrics 81, 281-317. https://doi.org/10.1016/S0304-4076(97)86569-4
Poterba, J. and L. Summers. (1988). "Mean-reversion in Stock Prices: Evidence and Implications." Journal of Financial Economics, Vol.22: 27-59. https://doi.org/10.1016/0304-405X(88)90021-9

Saikkonen, P. and Lütkepohl, H., (2002) Testing for a unit root in a time series with a level shift at unknown time, Econometric Theory 18, 313-348. https://doi.org/10.1017/S0266466602182053

Schwarz, G. (1978) Estimating the Dimension of a Model, Annals of Statistics, 6, 461-464. https://doi.org/10.1214/aos/1176344136

Whang, Y.-J., Kim, J., (2003). A multiple variance ratio test using subsampling. Economics Letters 79, 225-230. https://doi.org/10.1016/S0165-1765(02)00330-0

Wright, J.H., (2000). Alternative variance-ratio tests using ranks and signs. Journal of Business and Economic Statistics 18, 1-9. https://doi.org/10.1080/07350015.2000.10524842

Received on 29-11-2016

Accepted on 05-01-2017

Published on 25-01-2017

DOI: https://doi.org/10.6000/1929-7092.2017.06.02

(C) 2017 Assaf and Charif; Licensee Lifescience Global.

This is an open access article licensed under the terms of the Creative Commons Attribution Non-Commercial License (http://creativecommons.org/licenses/by-nc/3.0/) which permits unrestricted, non-commercial use, distribution and reproduction in any medium, provided the work is properly cited. 